\title{
Laboratory diagnosis of rheumatoid arthritis : a solid phase radioassay for IgG and IgM antiglobulins
}

\author{
L. J. NINEHAM, F. C. HAY, AND I. M. ROITT \\ From the Department of Immunology, The Middlesex Hospital Medical School, London WIP 9PG
}

SYNOPSIS A technique suitable for the routine estimation of IgM and IgG antiglobulins has been devised. The assay involves the binding of antiglobulins to plastic tubes coated with rabbit immunoglobulin: the amount of antiglobulin bound is then determined by adding radiolabelled antihuman IgG or IgM. The conditions for the assay have been examined and optimal incubation times and amounts of reagents established. Verification of the antibody nature of antiglobulin activity has been obtained. Both IgG and IgM antiglobulins were raised in virtually all seropositive rheumatoid arthritics, and most seronegative patients gave elevated values for either IgM or IgG rheumatoid factors. The use of an anti-light chain reagent as a screening test for total antiglobulins was investigated. These tests should prove valuable in diagnosis and permit quantitative evaluation of research studies.

In rheumatoid arthritis, antiglobulins or rheumatoid factors are present in both serum and synovial fluid. Although most laboratory diagnostic procedures depend on the measurement of IgM rheumatoid factors, it has become increasingly apparent that IgG antiglobulins play an important role in the pathogenesis of the synovial inflammatory response. Previously in this laboratory a procedure was developed for the detection of IgG antiglobulins involving elution from an immunoadsorbent, followed by quantification by single radial immunodiffusion (Torrigiani and Roitt, 1967). The immunoadsorbent was prepared from rabbit immunoglobulin cross-linked with benzidine. This technique, although reliable for estimating antiglobulins in each immunoglobulin class, was too time-consuming for routine use.

Therefore we have developed an assay which provides a rapid and simple means of routinely estimating antiglobulins of known class. Catt and Tregear (1967) have shown that plastic tubes may be used to bind proteins and we have used this principle for our radio assay. Antiglobulins are bound to rabbit immunoglobulin linked to the surface of plastic tubes; the amount of antiglobulin bound is then determined by adding radiolabelled antihuman IgG or IgM. In the present paper, we amplify an earlier preliminary report (Hay et al, 1975) and look

Received for publication 3 May 1976 at the possible use of anti-light chain as a screening reagent.

\section{Material and methods}

ANTISERA

Antihuman IgG, IgM, light chain, and ovalbumin were prepared by immunizing rabbits with purified Fc $\gamma$, IgM, light chains or ovalbumin (Hudson and Hay, 1976). The anti-IgM was rendered specific by adsorption with a cyanogen bromide-activated Sepharose-4B immunosorbent of cord serum. The antisera were checked for specificity by immunoelectrophoresis, Ouchterlony immunodiffusion, and radioimmunoassay. Purified antibody was prepared by adsorbing the antisera to cyanogen bromideactivated Sepharose-4B immunosorbents of human IgG, IgM, Fab or ovalbumin, followed by elution of the specific antibody with $0 \cdot 1 \mathrm{M}$ glycine- $\mathrm{HCl}$ buffer, pH 2.8. The purified antibodies were then radiolabelled with ${ }^{125}$ I (Na ${ }^{125}$ I, IMS 4, Radiochemical Centre, Amersham) by a modification of Hunter and Greenwood's (1962) method. Antibody $1 \mathrm{mg}$ in $1 \mathrm{ml}$ phosphate buffered saline (PBS), $0 \cdot 15 \mathrm{M}, \mathrm{pH} 7 \cdot 2$, was labelled with $500 \mu \mathrm{Ci}^{125} \mathrm{I}$ by adding $60 \mu \mathrm{g}$ chloramine T. After two minutes' incubation at room temperature $120 \mu \mathrm{g}$ sodium metabisulphite was added to stop the reaction. Free iodine was removed on a Sephadex G25 column. The labelled proteins were stored at $-20^{\circ} \mathrm{C}$. 
COATING OF THE PLASTIC TUBES

One-millilitre volumes of rabbit immunoglobulin (Miles Laboratories, Stoke Poges) at concentrations of $0 \cdot 1,1 \cdot 0,10,100,1000,5000$, and $10000 \mu \mathrm{g} \mathrm{ml}^{-1}$ in PBS were incubated in polystyrene tubes (LP3, Luckham Ltd, Sussex) for one hour at $37^{\circ} \mathrm{C}$ and overnight at $4^{\circ} \mathrm{C}$. After three washes with PBS, the tubes were incubated at room temperature for two hours with $2 \mathrm{ml}$ of $1 \%$ bovine serum albumin (Armour Pharmaceutical Co Ltd, Eastbourne) in PBS (BSA/PBS) to block any remaining free sites. After three more washes with PBS the tubes were inverted and stored at $4^{\circ} \mathrm{C}$.

\section{BINDING OF SERUM ANTIGLOBULINS}

The test sera were heated at $56^{\circ} \mathrm{C}$ for 30 minutes to inactivate complement. Duplicate 5, 25, 50, and 100 $\mu l$ samples were placed in the coated plastic tubes together with BSA/PBS to a final volume of $0.5 \mathrm{ml}$. Coated tubes containing $0.5 \mathrm{ml}$ BSA/PBS were used as background controls. The tubes were incubated at $37^{\circ} \mathrm{C}$ for one, three or five hours and then at $4^{\circ} \mathrm{C}$ for a half, one, two, four or six hours. Unbound proteins were removed by three washes with cold PBS.

\section{DETECTION OF BOUND ANTIGLOBULINS}

Human antibody bound to rabbit immunoglobulin coated tubes was detected by the addition of $0 \cdot 1$, 1.0 or $10.0 \mu \mathrm{g}$ of purified radiolabelled anti-IgG, IgM or light chain in $1 \mathrm{ml}$ BSA/PBS. Tubes were incubated at $37^{\circ} \mathrm{C}$ for one, three or five hours and then at $4^{\circ} \mathrm{C}$ for a half, one, two, four or six hours. Unbound labelled reagent was then removed by three washes with cold PBS. The tubes were counted in a gamma-ray spectrometer, the amount of radioactivity bound being a measure of the IgG, IgM or total antiglobulin in the patient's serum.

PAPAIN DIGEST OF HUMAN ANTIGLOBULINS Immunoglobulins were prepared from pooled rheumatoid arthritis sera by precipitation with $45 \%$ saturated ammonium sulphate. After dialysis against PBS containing $0.01 \mathrm{M}$ cysteine and 0.002 $M$ EDTA, the immunoglobulins were digested with papain $\left(2 \mathrm{mg} / 100 \mathrm{mg}\right.$ ) for four hours at $37^{\circ} \mathrm{C}$ and undigested immunoglobulin was removed by gel filtration on Sephadex G 100.

\section{PATIENTS}

Sera were obtained from 82 patients ( 25 men and 57 women) with rheumatoid arthritis whose sera reacted positively in the sheep cell agglutination test (SCAT) (Roitt and Doniach, 1969) and from 22 SCAT-negative rheumatoid arthritis patients (3 men and 19 women). All these patients conformed with the American Rheumatism Association criteria for probable, definite or classical rheumatoid arthritis.

Samples were also obtained from 12 patients with osteoarthritis (4 men and 8 women), six with traumatic injury ( 2 men and 4 women), and 130 normal controls working in the immunology음 laboratory ( 7 men and 6 women). All the sera were $\frac{\bar{c}}{\bar{\sigma}}$ frozen on the day of collection and kept at $-20^{\circ} \mathrm{C} \stackrel{\mathbb{Q}}{2}$ until tested.

\section{Results}

\section{VARIATION OF ASSAY CONDITIONS}

\section{Tube coating}

Using a fixed $50 \mu \mathrm{l}$ amount of patient's serum, there is maximum binding of IgG antiglobulins at a coating $\overrightarrow{\mathrm{N}}$ concentration of rabbit immunoglobulin between $1-$ and $10 \mu \mathrm{g} \mathrm{ml}^{-1}$ (fig 1). At higher coating concentra- $\overrightarrow{\mathrm{v}}$

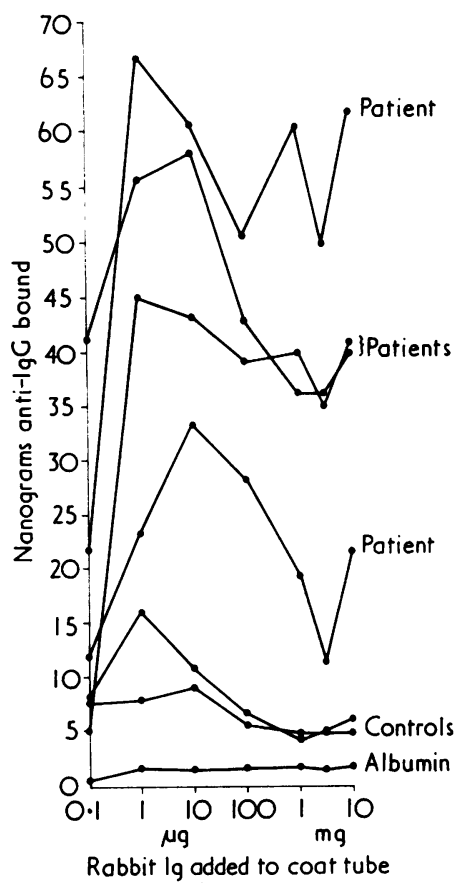

Fig 1 Effect of variation in concentration of rabbit Ig used for coating. Tubes were coated with $1 \mathrm{ml}$ volumes of solutions containing different amounts of rabbit immunoglobulin. Patient and control sera were then assayed by the standard procedure.

tions the amount of non-specific binding of the labelled reagents was negligible, as shown by the albumin control. In all further experiments $10 \mu \mathrm{g} \mathrm{ml}^{-1}$ rabbit immunoglobulin was used for coating.

Amount of patient's serum added

Varying amounts of patients' sera, from 5 to $100 \mu 1$ 
were added to the rabbit immunoglobulin coated tubes. Increasing antibody was detected up to $50 \mu \mathrm{l}$ but thereafter a plateau was reached (fig 2). Therefore $50 \mu \mathrm{l}$ was used in all subsequent assays.

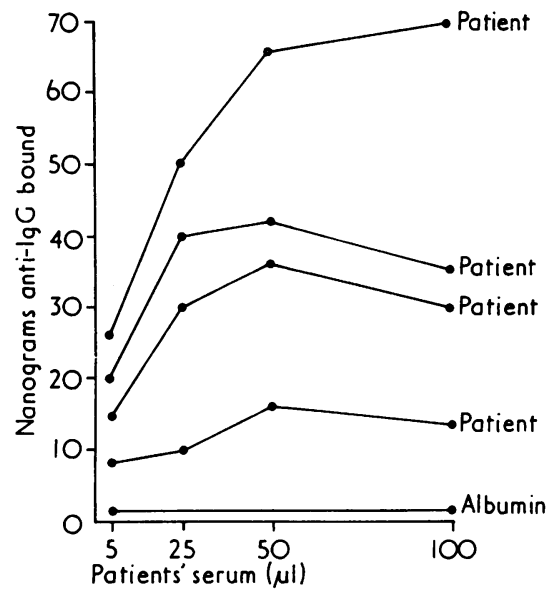

Fig 2 Dose response curves obtained with increasing amounts of patients' sera and an albumin control.

Time of incubation of patient's serum

Varying the incubation time of patients' sera at $37^{\circ} \mathrm{C}$ from one to five hours did not alter the amount of binding whereas a small increase in binding occurred on incubation at $4^{\circ} \mathrm{C}$ from half an hour up to two hours. Prolonged incubation to six hours did not give greater binding. Therefore one hour at $37^{\circ} \mathrm{C}$ and half an hour at $4^{\circ} \mathrm{C}$ was used routinely.

\section{Amount of anti-IgG added}

Human antiglobulins bound to the coated tubes were detected by incubating the tubes with 0.1 to 10.0 $\mu \mathrm{g} \mathrm{ml}^{-1}$ of purified anti-IgG. Figure 3 shows a linear relationship between the amount of anti-IgG added and the amount bound over this range. In all further assays $1 \mu \mathrm{g}$ was used.

Time of incubation with labelled reagent

Although significantly greater specific binding was obtained by incubating the anti-IgG reagent for five hours at $37^{\circ} \mathrm{C}$, good discrimination was already observed after one hour. Similarly, at $4^{\circ} \mathrm{C}$ an increase was seen up to six hours but discrimination was just as good at half an hour as at six hours. Therefore one hour at $37^{\circ} \mathrm{C}$ and half an hour at $4^{\circ} \mathrm{C}$ were used routinely.

\section{ROUTINE ASSAY CONDITIONS}

For routine use we selected the minimum incubation times and amounts of serum and reagents which

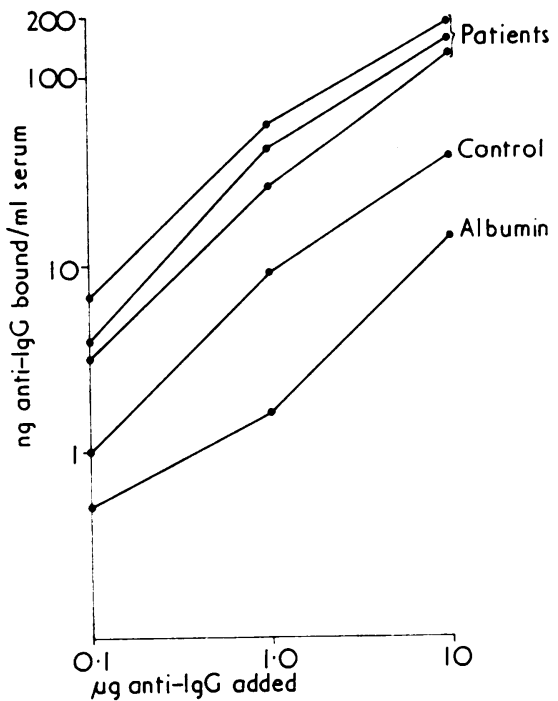

Fig 3 Dose response curves with increasing amounts of radiolabelled antihuman IgG tested against patient and control sera.

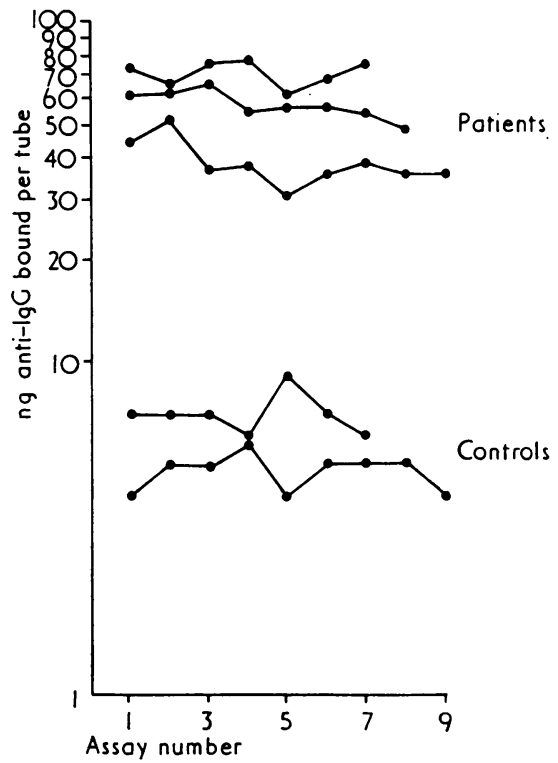

Fig 4 Assay reproducibility. Sera from patients and controls were tested on different days. The samples were refrozen between each assay. 
gave good discrimination between patients and controls. The tubes were coated with $10 \mu \mathrm{g}$ rabbit immunoglobulin in $1 \mathrm{ml}$ for one hour at $37^{\circ} \mathrm{C}$ and overnight at $4^{\circ} \mathrm{C}$. Fifty microlitres of patients' serum was incubated for one hour at $37^{\circ} \mathrm{C}$ and for half an hour at $4^{\circ} \mathrm{C}$, followed by $1 \mu \mathrm{g}$ of labelled antibody for one hour at $37^{\circ} \mathrm{C}$ and half an hour at $4^{\circ} \mathrm{C}$. The total incubation time was only three hours.

\section{REPRODUCIBILITY OF THE ASSAY}

Sera from three patients and two normal healthy controls were assayed on seven to nine different days. Between assays the samples were refrozen at $-20^{\circ} \mathrm{C}$. Figure 4 shows the assay to be highly reproducible, the mean coefficient of variance for the three patients being only $0 \cdot 11$.

\section{SITE OF ANTIGLOBULIN ACTIVITY}

The possibility existed that the binding of IgG reflected a property of a particular type of $\mathrm{Fc}$ region rather than conventional antibody activity associated with the Fab region. Table I shows that with whole

\begin{tabular}{lll}
\hline Antiglobulin preparation & \multicolumn{2}{l}{ Radiolabelled second antibody } \\
\cline { 2 - 3 } & Anti-light chain & Anti-Fc \\
\hline Whole IgG & $108^{1}$ & 125 \\
Papain digest & 59 & 3 \\
\hline
\end{tabular}

Table I Localization of the binding site for rabbit IgG in human IgG antiglobulin assayed by solid phase radioassay

'ng antibody bound per tube

IgG, isolated from a pool of patients' sera, antiglobulins were demonstrable by radioassay with both anti-light chain and anti-Fc antisera. However, with the IgG papain digest, activity was detected only by the anti-light chain reagent, demonstrating that the binding of antiglobulins was dependent solely on the Fab portion of the molecule.

IgM ANTIGLOBULINS IN RHEUMATOID

ARTHRITIS PATIENTS

Raised levels of IgM antiglobulins were obtained in all rheumatoid arthritis patients found to be SCATpositive and also in some SCAT-negative rheumatoid arthritis patients. Table II shows that the means of both groups were significantly different from the mean for the laboratory staff. Patients with traumatic injury or osteoarthritis gave even lower values than the laboratory staff control group. There was a significant correlation between the SCAT titre and the amount of IgM antiglobulin $(r=0.43 ; P<$ 0.001).

\begin{tabular}{lll}
\hline & $m g$ anti-IgM bound $1^{-1}$ serum \\
\cline { 2 - 3 } & $\begin{array}{l}\text { Mean } \pm \text { standard } \\
\text { error }\end{array}$ & $P(v$ staff $)$ \\
\hline SCAT-positive RA & $1.98 \pm 0.06$ & $<0.01^{1}$ \\
SCAT-negative RA & $\mathbf{0 . 8 7} \pm 0.08$ & $<0.01$ \\
Osteoarthritis & $\mathbf{0 . 3 7} \pm 0.06$ & $<0.1$ \\
Staff & $\mathbf{0 . 6 0} \pm 0.06$ & - \\
Traumatic injury & $\mathbf{0 . 4 6} \pm 0.10$ & NSD \\
\hline
\end{tabular}

Table II Serum IgM antiglobuiins in patients with rheumatoid arthritis and controls

NSD = not significantly different

1By Wilcoxon test for two samples

\section{IgG ANTIGLOBULINS}

IgG antiglobulins were also detected in both SCAT- तु positive and SCAT-negative rheumatoid arthritis $\vec{N}$ groups (table III), the means being significantly

\begin{tabular}{lll}
\hline & \multicolumn{2}{l}{$m g$ anti-IgG bound $1^{-1}$ serum } \\
\cline { 2 - 3 } & $\begin{array}{l}\text { Mean } \pm \text { standard } \\
\text { error }\end{array}$ & $P(v$ staff $)$ \\
\hline SCAT-positive RA & $0.48 \pm 0.03$ & $<0.01$ \\
SCAT-negative RA & $0.29 \pm 0.05$ & $<0.01$ \\
Osteoarthritis & $0.13 \pm 0.01$ & NSD \\
Staff & $0.12 \pm 0.01$ & - \\
Traumatic injury & $0.10 \pm 0.01$ & NSD \\
\hline
\end{tabular}

Table III Serum IgG antiglobulins in patients with rheumatoid arthritis and controls

NSD $=$ not significantly different

raised compared to the mean for control groups. Not all rheumatoid arthritis patients had raised $\stackrel{2}{\overrightarrow{7}}$ levels of both IgG and IgM antiglobulins, but $96 \%$ 을 of the samples examined gave raised values (over $2 \frac{3}{2}$ standard deviations above the combined mean of the laboratory staff and traumatic injury patients) for either IgG or IgM antiglobulins (fig 5).

In seropositive rheumatoid arthritis there was a $\dot{0}$ good correlation between the amounts of IgG and IgM antiglobulins $(r=0.64 ; P<0.001)$. However, $\frac{\rho}{2}$ there was little correlation in seronegative rheumatoid arthritis $(r=0.12 ; 0.6>P>0.5)$. The SCAT titre 음 in the seropositive patients correlated just as well with the level of $\operatorname{IgG}$ antiglobulin $(r=0.44 ; \mathrm{P}<$ 을. 0.001 ) as it had with the IgM antiglobulins.

\section{TOTAL ANTIGLOBULINS}

As the light chains are common to all immunoglobulin classes, we have tested some of the sera with anti-light chain as the radiolabelled reagent too detect antiglobulins in all classes. Figure 6 shows $\bar{\varnothing}$ raised levels of antiglobulins in all SCAT-positive $\stackrel{\oplus}{+}$ and $50 \%$ of SCAT-negative rheumatoid arthritis $\underline{T}$ patients compared with the low levels in laboratory staff and osteoarthritis and traumatic injury patients. 


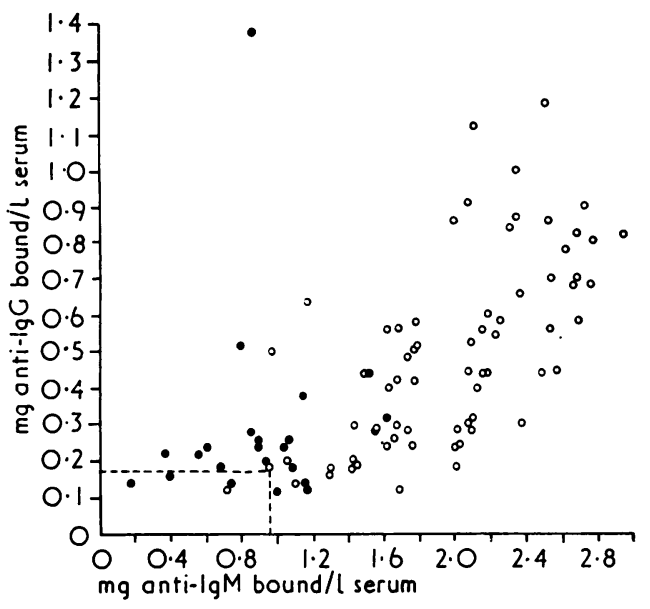

Fig 5 Correlation between IgG and IgM antiglobulins in rheumatoid arthritis. The area of normality is indicated by the dotted lines placed at 2 standard deviations above the means for IgG and IgM antiglobulins in the combined control group of laboratory staff and traumatic injury patients: $O=$ seropositive rheumatoid arthritis; $\mathbf{O}=$ seronegative rheumatoid arthritis.

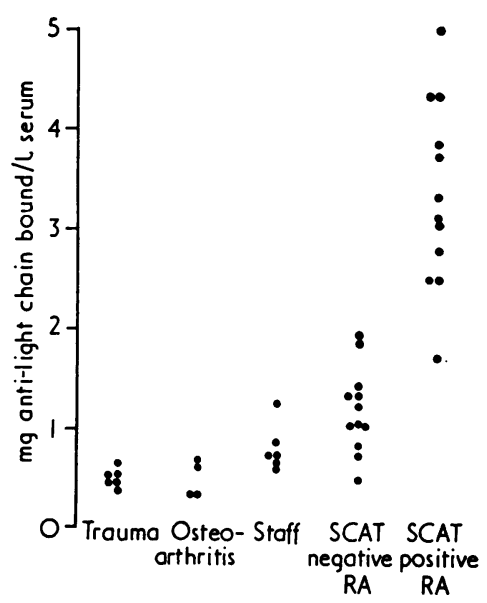

Fig 6 Antiglobulins in the sera of patients with $S C A T$-positive and SCAT-negative rheumatoid arthritis, traumatic injury, and osteoarthritis and in normal controls detected by radiolabelled antihuman light chain reagent.

On examining the contribution of different classes to the anti-light chain results in the combined rheumatoid arthritis groups, we found a much closer correlation between the anti-IgM and anti-light chain levels $(r=0.81 ; P<0.001)$ than between the anti-IgG and anti-light chain levels $(r=0.365$; $0 \cdot 1<\mathrm{P}<0.2$ ).
CONTROL FOR BINDING OF NORMAL RABBIT IgG BY I gM RHEUMATOID FACTOR It was possible that the IgM rheumatoid factors might attach to the rabbit immunoglobulins on the tube through only some of its Fab regions, leaving the others free. These could then combine with the Fc region of the radiolabelled rabbit anti-IgG used for detecting IgG antiglobulins. To test this hypothesis, radiolabelled purified rabbit antiovalbumin was added to the tubes in parallel with anti-IgG and anti-IgM. Table IV shows that only

\begin{tabular}{llll}
\hline Serum & Anti-IgM & Anti-lgG & Anti-ovalbumin \\
\hline SCAT-positive RA & $118^{1}$ & 63 & $1 \cdot 7$ \\
SCAT-positive RA & 134 & 39 & $1 \cdot 3$ \\
SCAT-negative RA & 25 & 30 & $0 \cdot 15$ \\
Laboratory staff & 34 & $6 \cdot 6$ & $0 \cdot 15$ \\
BSA control & 2 & $1 \cdot 2$ & $0 \cdot 12$ \\
\hline
\end{tabular}

Table IV Validation of IgG antiglobulin results

'ng antibody bound per tube

Sera from patients and a normal control were tested for antiglobulins by the radioassay with the use of different rabbit antibodies for the final stage

very low levels of binding were obtained with antiovalbumin even in the presence of large amounts of rheumatoid factor.

\section{Discussion}

In the laboratory the diagnosis of rheumatoid arthritis traditionally depends on the detection of rheumatoid factors in the classical latex and sheep cell agglutination tests. Unfortunately, positive results with these techniques are obtained only with $19 S$ IgM rheumatoid factors. However, there is now increasing evidence that IgG antiglobulins may be more important in the pathogenesis of rheumatoid arthritis. Winchester et al (1970) have shown that complexes in the synovial fluid of rheumatoid arthritis patients are composed almost entirely of IgG, and Winchester (1975) has since shown that at least $50 \%$ of this IgG has antiglobulin activity. The importance of these antiglobulin complexes has been demonstrated by their ability to activate com plement and to cause a reduction in total haemolytic complement within the synovial fluid. Furthermore, Pope et al (1974) have shown that the intermediate complexes found in the serum of three rheumatoid patients were composed entirely of self-associated IgG antiglobulins, while Theofilopoulos et al (1974) have evidence which strongly suggests that IgG antiglobulins play a part in the development of rheumatoid vasculitis.

To simplify the detection of IgG antiglobulins, 
several workers have modified the immunoadsorbent procedures (Bianco et al, 1971; Bianco et al, 1974; Florin-Christensen et al, 1974). However, all of these techniques are still time-consuming, and some of the immunoadsorbents, particularly activated agarose (Bianco et al, 1974), give unacceptably high binding of IgG with normal controls. In the present work we have found that binding to antigen-coated plastic tubes provides a convenient and rapid assay which is free from these problems. Repeated testing of samples on up to nine different occasions has shown the assay to be highly reproducible.

In determining the parameters for the assay, we have found the concentration of rabbit immunoglobulin used for coating the tubes to be important, since less antiglobulin is detected at coating strengths both above and below the optimum. In order to obtain low backgrounds with controls, it is essential that only purified antibody should be used as the radiolabelled reagent. Most other variables can be considerably altered while still giving good discrimination, and thus for our routine assay we have chosen those conditions most economical with respect to incubation times and amounts of reagents. However, the results show that for increased sensitivity, prolonged incubation is required and a saturating amount of radiolabelled antibody should be added. Preliminary studies have shown that the use of an enzyme-linked anti-Ig in place of the iodine labelled antibody is perfectly feasible.

Our technique has enabled us to investigate the site of antiglobulin activity within the immunoglobulin molecule. After papain digestion of immunoglobulin from rheumatoid arthritis patients, only the Fab regions bound to the rabbit immunoglobulin coated tubes. Thus it seems likely that we are detecting a true antigen-antibody reaction in our assay rather than non-specific adherence through the Fc region.

Virtually all the SCAT-positive sera gave raised IgM and IgG antiglobulin values. Most SCATnegative sera also showed raised antiglobulins though the mean was lower than that for the SCATpositive group. When radiolabelled anti-light chain was used as a screening reagent for total antiglobulins, all the SCAT-positive and many of the SCAT-negative sera had raised levels. However, as our anti-light chain results showed a greater correlation with IgM than with IgG antiglobulins, we have found that with SCAT-negative sera, it is also necessary to look for IgG antiglobulins using an
anti-IgG reagent.

Since the test allows the rapid estimation of both IgM and IgG antiglobulins it should be of values routinely in the diagnosis of adult rheumatoido arthritis and Still's disease.

We thank Mrs Noemi Ron for assistance with the anti-light chain assays. We are grateful to Misso Hilary Fischler for the preparation of the manuscript. This work was supported by the Medical Research Council of Great Britain.

\section{References}

Bianco, N. E., Dobkin, L. W., and Schur, P. H. (1974) $\vec{N}$ Immunological properties of isolated IgG and IgM anti-

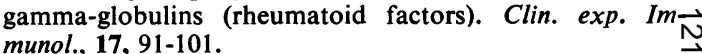

Bianco, N. E., Panush, R. S., Stillman, J. S., and Schuro P. H. (1971). Immunologic studies of juvenile rheumatoid arthritis. Arthr. and Rheum., 14, 685-696.

Catt, K. J. and Tregear, G. W. (1967). Solid-phase radio immunoassay in antibody-coated tubes. Science, 158 1570-1572.

Florin-Christensen, A., Arana, R. M., Morteo, O. G.? Roux, M. E. B., and Hubschuer, O. (1974). IgG, IgA IgM and IgD antiglobulins in juvenile rheumatgidarthritis. Ann. rheum. Dis., 33, 32-34.

Hay, F. C., Nineham, L. J., and Roitt, I. M. (1975). Routhe assay for detection of IgG and IgM antiglobulins seronegative and seropositive rheumatoid arthritis. $B+1$ ? med. J., 3, 203-204.

Hudson, L. and Hay, F. C. (1976). Practical Immunolog Blackwell, Oxford.

Hunter, W. M. and Greenwood, F. C. (1962). Preparation of iodine-131 labelled human growth hormone of high specific activity. Nature (Lond.), 194, 495-496.

Pope, R. M., Teller, D. C., and Mannik, M. (1974). The molecular basis of self-association of antibodies to IgG (rheumatoid factors) in rheumatoid arthritis. Proc. nafo Acad. Sci. (Wash.), 71, 517-521.

Roitt, I. M. and Doniach, D. (1969). Tests for rheumatoi市 factors. In WHO Manial of Autoimmune Serology, pp: 27-31. WHO, Geneva.

Theofilopoulos, A. N., Burtonboy, G., LoSpalluto, J. J. and Ziff, M. (1974). IgM rheumatoid factor and lovo molecular weight IgM: an association with vasculitis? Arthr. and Rheum., 17, 272-284.

Torrigiani, G. and Roitt, I. M. (1967). Antiglobulin factor? in sera from patients with rheumatoid arthritis and normaf subjects. Ann. rheum. Dis., 26, 334-340.

Winchester, R. J. (1975). Characteristics of IgG complexe in patients with rheumatoid arthritis. Ann. N.Y. Acadb Sci., 256, 73-81.

Winchester, R. J., Agnello, V., and Kunkel, H. G. (1970) Gamma globulin complexes in synovial fluids of patientso with rheumatoid arthritis: partial characterization and relationship to lowered complement levels. Clin. exp Immunol., 6, 689-706. 